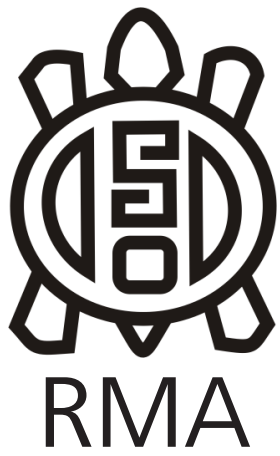

Arqueología

\title{
Tecnología lítica y uso del espacio durante el Holoceno medio en la cuenca del lago Cardiel (centro-oeste de Santa Cruz)
}

\author{
Lithic technology and land use during the Middle Holocene in the Lake \\ Cardiel basin (central-west Santa Cruz)
}

Agustín Mariano Agnolin*

*CONICET, Instituto Nacional de Antropología y Pensamiento Latinoamericano. E-mail: agusagnolin@yahoo.com.ar

\begin{abstract}
Resumen
La cuenca del lago Cardiel ha sido objeto de una extensa serie de investigaciones acerca de su proceso de poblamiento y la relación entre el cambio climático/ambiental y social a lo largo del Holoceno. Estas investigaciones se han centrado en el Holoceno tardío, el cual posee un abundante registro arqueológico en la región. En cambio, el Holoceno medio, entre los ca. 7500 y 3000 años calibrados AP, presenta un registro arqueológico menos abundante y muestra el inicio de la tardía colonización de la cuenca. En este trabajo se analiza la composición y distribución de la tecnología lítica perteneciente a este período, se discute la funcionalidad de los diferentes espacios de la cuenca y las estrategias de movilidad que habrían sido empleadas por los grupos cazadores locales. Se concluye que la ocupación de esta región se caracterizaría por un uso similar de sus distintos ambientes, asociado a una tecnología lítica con una baja inversión de energía en su manufactura y el uso de rocas inmediatamente disponibles. Los grupos locales habrían tenido una movilidad con un menor componente logístico que la registrada para momentos posteriores.
\end{abstract}

Palabras Clave: Holoceno medio; Proceso de poblamiento; Tecnología lítica; Cazadores-recolectores; Movilidad.

\begin{abstract}
The Lake Cardiel basin has been the subject of an extensive series of investigations about its peopling process and the relationship between climatic, environmental and social change throughout the Holocene. These investigations have focused on the late Holocene, which has an abundant archaeological record in the region. In contrast, the middle Holocene, between ca. 7500 and 3000 years calibrated BP, shows the beginning of the colonization of the basin and presents a less abundant archaeological record. In this paper is analyzed the composition and distribution of the middle Holocene lithic technology, the functionality of the different spaces of the basin and the mobility strategies that would have been used by the local hunting groups. It is concluded that the occupation of this region would be characterized by a similar use of its different environments, associated with a lithic technology with a low investment of energy in its manufacture and the use of immediately available rocks. The local groups would have had mobility strategies with a lower logistical component than recorded for later moments.
\end{abstract}

Keywords: Middle Holocene; Lithic technology; Peopling process; Hunter gatherers; Mobility.

\section{Introducción}

El lago Cardiel ocupa una cuenca endorreica situada en la estepa del centro-oeste de Santa Cruz (Figura 1). El mismo presenta una extensa historia de investigaciones que han detectado ocupaciones humanas desde hace 7500 años calibrados AP (Goñi, et al. 2014). Asimismo, el lago constituye un archivo paleoambiental de gran relevancia para el hemisferio sur y ha sido estudiado por diversos proyectos que permitieron establecer una sucesión de cambios climático/ambientales desde fines del Pleistoceno (Ariztegui et al., 2001, 2008; Gilli et al., 2001, 2005; Quade y Kaplan,
2017; Stine, 2000; Stine y Stine, 1990, entre otros). Las investigaciones arqueológicas han utilizado esta información paleoambiental para proponer un modelo de poblamiento de la región que enfatiza la relación entre el cambio climático/ambiental y el social, haciendo foco especialmente en el Holoceno tardío (Cassiodoro, et al., 2013; Goñi 2010; Goñi et al., 2004, 2005, 2014). Por otra parte, el Holoceno medio ha sido menos estudiado y al momento se han llevado a cabo un menor volumen de trabajos específicos sobre éste. En esta contribución se analizará la tecnología lítica perteneciente a las ocupaciones del Holoceno medio, con el objetivo de discutir el uso del espacio y las estrategias de movilidad 
implementadas por los grupos de cazadores que ocuparon la cuenca durante dicho período. La dinámica de poblamiento de la región se habría dado en un espacio previamente no ocupado, que, por causas climáticas, ambientales y posiblemente demográficas, permaneció marginal al proceso de colonización (sensu Borrero 1989-1990) hasta el Holoceno medio.

Los estudios paleoambientales en la región señalaron variaciones en la disponibilidad de humedad desde fines del Pleistoceno. De este modo, entre los 8500 y 7400 años calibrados AP hay un marcado descenso de los niveles lacustres, que permanecían elevados (55 m por encima de los actuales) desde inicios del Holoceno. Este período de sequía concluye con un nuevo ascenso de las aguas (entre 40 y 22 m por encima de la cota actual) entre los 7400 y 5100 años cal. AP que inundó sectores como los Médanos del este y sur y las desembocaduras de los ríos Cardiel y Bayo (Ariztegui et al., 2008; Gilli et al., 2001, 2005; Markgraf et al., 2003; Quade y Kaplan, 2017; Stine y Stine, 1990; Stine, 1994). A partir de los 5100 años calibrados AP se daría la intensificación de los vientos westerlies (Gilli et al., 2005), asociados a un progresivo desecamiento que tendría picos hacia el 3000 AP y 900 calibrados AP, continuando hasta la actualidad (Stine y Stine, 1990; Stine 1994, 2000). Estas variaciones habrían generado un ambiente caracterizado en los momentos más húmedos por una mayor cobertura herbácea y una elevada disponibilidad y dispersión de las fuentes de agua, pasturas y guanacos. En contraste, en momentos más áridos habría un paisaje fragmentado, de estepa arbustiva, con parches de disponibilidad diferencial de recursos. A pesar de estas variaciones, el guanaco habría continuado siendo el recurso principal (Goñi, 2010; Rindel, 2009).

Las investigaciones arqueológicas han propuesto que estas variaciones afectaron el proceso de poblamiento de la región, principalmente la movilidad y uso del espacio de las poblaciones locales (Agnolin, 2019; Belardi, et al. 2003; Cassiodoro, et al. 2013; Goñi, 2000, 2010; Goñi y Belardi, 2014, Goñi et al., 2004). Las primeras ocupaciones de la cuenca ocurren durante el Holoceno medio, en un marcado desfasaje con respecto a las regiones vecinas como el Parque Nacional Perito Moreno (PNPM), la Meseta Central, el lago San Martín, o la cuenca del río Pinturas ocupadas desde el Pleistoceno $u$ Holoceno temprano (Aschero et al., 2005; Belardi et al., 2013; Gradin et al., 1987; Mosquera, 2018; Sacchi et al., 2016, entre otros). Se ha propuesto que este tardío poblamiento de la región se debería a que en momentos previos los altos niveles de las aguas habrían constituido una barrera a la circulación de poblaciones (Goñi y Belardi, 2014). Estudios previos sobre estas ocupaciones han señalado que las mismas se limitaron a puntos específicos del paisaje debido a que los sectores más bajos se encontraban ocupados por amplios cuerpos lacustres. La tecnología de estas ocupaciones se caracterizaría por el uso de rocas locales y obsidiana, así como una escasa formatización de los artefactos líticos y el uso de puntas apedunculadas triangulares y lanceoladas (Agnolin, 2019, 2020; Cassiodoro, et al. 2014; Cassiodoro et al., 2020; Piriz, 2004).

Hacia el Holoceno tardío (post 3000 años AP), en el marco de un paisaje más árido y fragmentado, el lago Cardiel y otras cuencas lacustres bajas (lagos Posadas/ Pueyrredón, Salitroso y Tar) funcionaron como espacios de concentración de poblaciones en los que los grupos humanos habrían focalizado sus asentamientos, disminuyendo su movilidad residencial, y aumentando su movilidad logística (Goñi, 2010; Goñi y Barrientos, 2004; Goñi et al., 2005; Re et al., 2017, entre otros). La tecnología de este período se caracteriza por la incorporación de la cerámica, el arco y flecha y las puntas de proyectil con pedúnculo y aletas (Cassiodoro, 2016; Cassiodoro et al., 2014, 2020). Los diversos ambientes de la cuenca del Cardiel habrían sido utilizados de manera diferencial (Belardi et al., 2003; Goñi, 2010; Goñi et al., 2014), dejando un registro arqueológico caracterizado por una marcada heterogeneidad en la distribución de artefactos en las diferentes geoformas (Belardi et al., 2003; Cassiodoro et al. 2014; Goñi 2010).

De acuerdo a esto, mientras que para los últimos 3000 años calibrados AP se ha propuesto un complejo proceso de poblamiento, para el Holoceno medio aún hay limitados trabajos sobre sus características. De este modo, aspectos como el uso del espacio y la movilidad, aún no han sido evaluados en profundidad, así como la relación entre estas estrategias y las condiciones climático/ ambientales particulares de este período. Este trabajo se propone abordar estas problemáticas desde el estudio de la tecnología lítica, la cual se muestra como una vía privilegiada para acceder a las estrategias de los grupos humanos del pasado (Nelson, 1991).

\section{La región y sus materias primas}

El lago Cardiel es una cuenca endorreica de clima árido y marcada estacionalidad, cubierta por una vegetación de estepa arbustiva y herbácea (Morello et al., 2012). Ha sido dividida para su abordaje arqueológico en cinco áreas (Figura 1) con características diversas (Belardi et al., 2003; Goñi et al., 2014). En el oeste de la cuenca y enmarcado por el río Cardiel hacia el sur y el arroyo Bayo hacia el norte, se encuentran los Cañadones de arenisca (entre 300 y 700 msnm, Figura 1.1), caracterizados por la presencia de aleros y con escasas fuentes de agua. En contraste, los valles de los ríos que lo bordean disponen de abundante agua, así como materias primas líticas, reparo y vegetación (Goñi et al., 2014). En el noroeste del lago, el sector de Meseta baja (ca. 500 msnm, Figura 1.2) presenta vertientes, médanos y abundante vegetación arbustiva en su borde. Es un espacio que concentra grandes grupos de guanacos durante el otoño (Agnolin 
y Guichón, 2018). Al sur del lago se encuentra también un sector de Meseta baja, el cual recientemente ha sido incorporado a las investigaciones y no será abordado en este trabajo. Al norte de la cuenca se ubica el sector de Pie de meseta, compuesto por lomas y hondonadas con una topografía propicia para la caza y materias primas líticas diversas (Figura 1.3). El sur y este del lago presentan sectores de médanos (270 msnm, Figura 1.4 y 1.5) con una importante variedad de recursos animales, vegetales y reparo, así como materias primas líticas en sus cercanías. Finalmente, y por fuera del área considerada en este trabajo, hacia el norte y sur se encuentran mesetas altas de entre 700 y 1200 msnm (Strobel y Cardiel Chico/San Adolfo, Figura 1.6). Estas son espacios de parición de los guanacos durante el verano, ya que poseen abundantes fuentes de agua y pastos, aunque con acceso restringido a la primavera y el verano debido a las fuertes nevadas invernales.

La estructura de recursos líticos regional incluye abundantes materias primas de calidades aptas para la talla, que ha sido publicadas de manera detallada en trabajos previos (Agnolin et al., 2018; Belardi et al., 2003, 2015; Cassiodoro et al., 2014). La limolita de buena y muy buena calidad se encuentra disponible en forma de guijarros y bloques en el sector de Cañadones, principalmente en el valle y desembocadura del arroyo Bayo y en menor medida y presentando una menor calidad, en el valle del río Cardiel. Asimismo, hay guijarros y bloques de una roca sedimentaria similar a la limolita, de calidad regular a buena, en un pequeño sector de la Meseta baja. Dado que no es posible diferenciar a ojo desnudo esta roca de la limolita, se las consideró como una misma materia prima, si bien es posible que análisis futuros determinen que se trata de rocas diferentes. Los basaltos de grano grueso, de mala calidad para la talla de artefactos con filo, pero útiles para la confección de bolas y artefactos de molienda, se encuentran disponibles en el cauce del arroyo Bayo, el Pie de meseta y los sectores de Médanos del este y sur, en forma de bloques y guijarros. El basalto de grano fino y la toba, de calidades muy buena y buena, resultan abundantes, especialmente en los sectores de Médanos del este y sur, si bien cuentan con diversos depósitos en todas las geoformas. Se presentan en tamaños diversos, en guijarros y bloques. Por otra parte, dispersas a lo largo de toda la cuenca se encuentran guijarros de rocas silíceas de buena calidad para la talla, junto con riolitas, cuarcitas, calcedonias, xilópalo y dacitas, asociados a los llamados mantos de rodados tehuelches. En términos generales resultan más escasas y son de menor tamaño que los basaltos, tobas y limolitas. De acuerdo a esto, puede considerarse que todas las geoformas poseen materias primas de buena calidad para la talla, si bien los Cañadones concentran una mayor abundancia y diversidad. Cabe remarcar que, durante el Holoceno medio, los niveles altos del lago cubrieron parte de los depósitos de limolita ubicados a orillas del lago Cardiel, así como los basaltos y tobas de los Médanos del este y sur y de la Meseta baja, si bien la mayoría de sus depósitos no se habrían visto afectados.

Finalmente, por fuera de la cuenca se encuentra disponible la obsidiana negra de la Pampa del Asador, a unos $90 \mathrm{~km}$ en dirección norte del área de estudio (Espinosa y Goñi, 1999). Dicho espacio es, asimismo, muy rico en rocas silíceas y basaltos de grano fino (Cassiodoro et al., 2019).

\section{Aspectos teóricos y metodológicos}

Se empleó la perspectiva de la organización tecnológica (Binford, 1977, 1979; Nelson, 1991), cuyo énfasis en las estrategias y en la interacción entre diferentes variables ambientales y sociales permite articular aspectos de la subsistencia y movilidad con la tecnología. Asimismo, se incorporaron a la discusión los estudios sobre movilidad, uso del espacio y tecnología desarrollados desde una

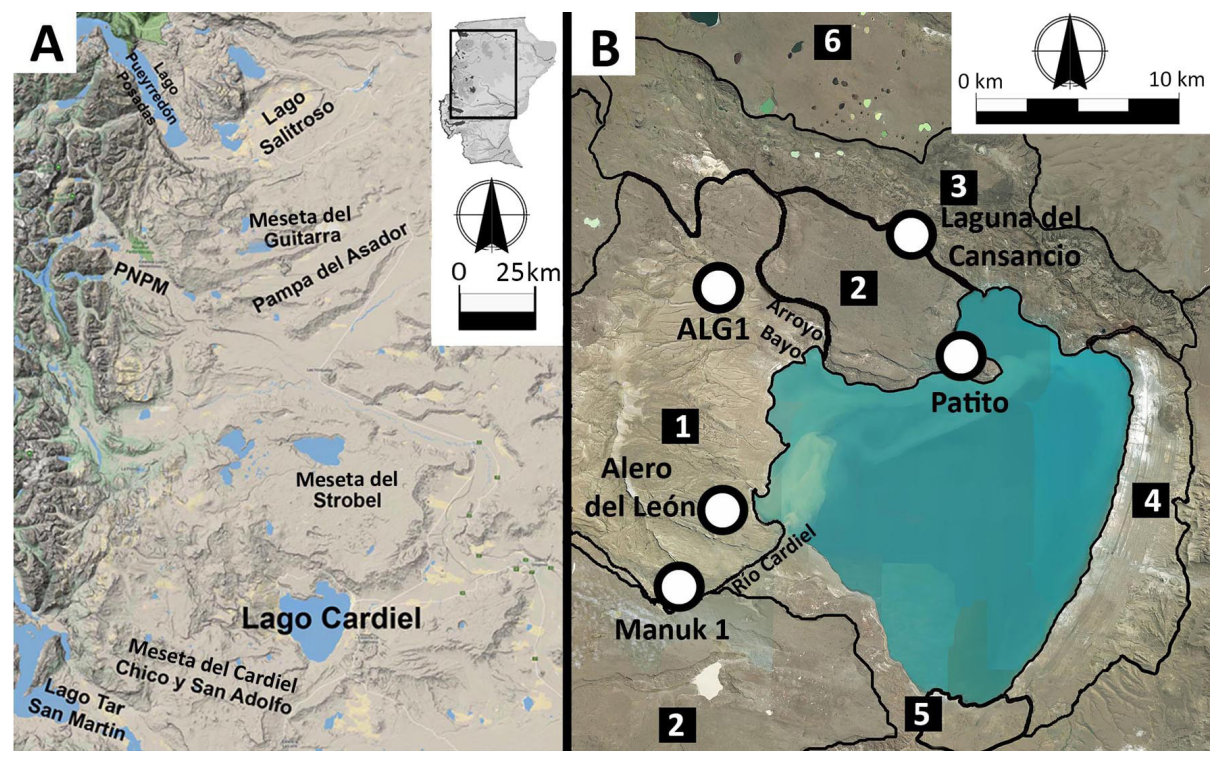

Figura 1: Región de estudio. A: ubicación de la cuenca del Cardiel y las regiones mencionadas en el texto, B: ubicación de los sitios dentro de la cuenca y geoformas. Referencias: 1: Cañadones, 2: Mesetas bajas, 3: Pie de meseta, 4: Médanos del este, 5: Médanos del sur, 6: Meseta alta.

Figure 1: Study region. A: location of the Cardiel basin and the regions mentioned in the text, B: location of the sites within the basin and geoforms. References: 1: Cañadones, 2: Low plateaus, 3: Plateau foot, 4: Eastern dunes, 5: Southern dunes, 6: High plateau. 
perspectiva ecológica y evolutiva por diversos autores (Andrefsky, 1994; Bettinger et al., 2006; Binford, 1977, 1979, 1980, 2001; Escola, 2004; Gould, 1980; Kelly, 1983, 2013).

Se utiliza un acercamiento distribucional (Dunnell y Dancey, 1983), se considera al artefacto como la unidad fundamental, haciendo énfasis en la distribución y composición del registro arqueológico. La escala utilizada es mesorregional (Dincauze, 2000), evaluando la cuenca en su conjunto, así como las diferentes geoformas y sitios.

Para el análisis artefactual se empleó la propuesta de Aschero (1975, 1983; Aschero y Hocsman 2004), segmentando el conjunto en clases tipológicas y tipos artefactuales. Buscando evaluar la relación entre el tamaño de muestra y el número de clases representadas se utilizó el coeficiente de correlación de Pearson. Asimismo, con el objeto de discutir las actividades de talla se consideraron entre los artefactos formatizados, filos naturales con rastros complementarios (FNCRC) y desechos de talla los tipos de forma base, mientras que entre los núcleos se consideró el tipo de extracciones presentes (laminares o lascas) y su frecuencia con relación a otros tipos de artefactos. Para esto último, se dividió su frecuencia por la de artefactos formatizados (Crivelli Montero y Fernández, 2004). Para la caracterización de los conjuntos artefactuales no se utilizaron los fragmentos indiferenciados de artefactos, ya que, si bien aportan información, no son una categoría funcional equiparable a otras. Por otra parte, se evaluaron las materias primas en todos los tipos de artefactos, agrupando a las calcedonias, riolitas, dacitas y cuarcitas, que se presentan en baja frecuencia, en la categoría "Otras". Finalmente, se utilizó la categoría rocas silíceas para incluir a una variedad de rocas que incluye los jaspes, ópalos y cherts.

En el caso del sitio Patito se tuvo en cuenta que los materiales se encuentran fuertemente alterados por el agua y presentan una elevada proporción de rastros de abrasión y fracturas en sus filos (Piriz, 2004). De acuerdo a esto, durante el análisis se siguió un criterio conservador, identificando como artefactos formatizados sólo aquellos que conservaban rasgos claros de intencionalidad humana (filos regulares, retoques parejos y continuos). Dadas estas precauciones y el hecho de que la abrasión pudo borrar o alterar significativamente algunos rasgos como los microrretoques, es probable que la verdadera abundancia de tipos artefactuales como los FNCRC o los artefactos de formatización sumaria (AFS), se encuentre subestimada.

\section{Muestra y cronología}

En la cuenca se han detectado únicamente seis sitios con cronologías asignables al Holoceno medio, de los cuales proviene la muestra analizada (Figura 1). De estos sitios, Manuk 1, Alero Los Guanacos 1 (ALG1) y Alero del León, se ubican en los Cañadones, Gerasín 1 y Patito, en la Meseta baja y Laguna del Cansancio, en el Pie de meseta (Figura 1). Manuk 1, ALG1, Alero del León, y Gerasín 1 se encuentran en aleros o al reparo de paredones, mientras que Patito es un sitio a cielo abierto y Laguna del Cansancio se distribuye a lo largo de un conjunto de bloques, paredones y derrumbes que le otorgan reparo. El material lítico proveniente de estos sitios está compuesto principalmente por desechos de talla (n: 1433), seguidos en frecuencia por los artefactos formatizados (n: 166), FNCRC (n: 56) y núcleos (n: 42). Los conjuntos poseen diferentes tamaños y se destaca la muestra proveniente de ALG1 (n: 1251), seguida por la de Patito (n: 201) y Manuk 1 (n: 143). Los sitios han sido descriptos en mayor amplitud en trabajos previos (Agnolin 2020; Cassiodoro et al. 2014; Martínez et al 2012; Piriz 2004; Rindel et al. 2010), a continuación, se describen sus principales características.

Manuk 1 es un alero ubicado en el valle del río Cardiel en el que se excavaron $3 \mathrm{~m}^{2}$ y un sondeo, detectándose materiales líticos arqueofaunístico, vegetales y estructuras de combustión hasta los $150 \mathrm{~cm}$ de profundidad (Cassiodoro et al., 2014). Su talud presenta abundantes artefactos líticos en superficie producto de la talla de limolita, con cronologías asignables tanto al Holoceno medio como al tardío, en base al tipo de puntas de proyectil recuperadas (Agnolin, 2016, 2019). El material faunístico recuperado en el Holoceno medio consiste en exiguos huesos de guanaco y escasos ejemplares de otras especies (Rindel y Bourlot, 2014). La ocupación incluye los fechados más tempranos de la cuenca, así como cronologías posteriores. De acuerdo a esto, se dividió el conjunto en dos segmentos, el primero, que será incluido en este trabajo, abarca entre ca. 7600-7500 y 3400-2300 años calibrados AP, mientras que el segundo abarca desde esta fecha hasta los ca. 700 a 900 años calibrados AP (Goñi et al., 2014). Los materiales líticos recuperados y analizados consisten en 14 artefactos formatizados, dos FNCRC, dos núcleos y 125 desechos.

El Alero del León, ubicado en los Cañadones, posee un importante conjunto de representaciones rupestres (Guichón, 2018). Se efectuaron tres excavaciones totalizando $2,5 \mathrm{~m}^{2}$, en las que se recuperaron materiales arqueofaunísticos y líticos. Los primeros consisten en escasos restos de guanaco (Rindel y Bourlot, 2014). Se obtuvieron fechados que ubican el comienzo de las ocupaciones hacia los ca. 8100-6400 años calibrados AP, seguidos por cronologías de ca. 3900-3600, 22002000, 1500-500 y 300-200 años calibrados AP (Goñi, 2000-2002; Goñi et al., 2004). Los materiales analizados en este trabajo ( $n$ desechos: 35 ) provienen del nivel fechado en ca. 3900-3600 años calibrados AP y los niveles no fechados ubicados inmediatamente por debajo de este. El fechado más temprano se encuentra 
hecho sobre un elemento óseo de guanaco con marcas antrópicas, pero no presenta ninguna asociación con materiales líticos.

ALG1 es un alero ubicado en los Cañadones, junto al valle del arroyo Bayo y en el cual se excavaron $6 \mathrm{~m}^{2}$, recuperando abundantes materiales líticos, arqueofaunísticos, vegetales y estructuras de combustión (Agnolin, 2020; Martínez et al. 2012). Los restos óseos pertenecen en su casi totalidad a un bajo número de guanacos (Rindel y Bourlot, 2014). Por otra parte, el análisis del material arqueobotánico señala la utilización de los vegetales locales en estado verde, posiblemente para generar humo (Pasqualini, 2014). Se ha obtenido una serie de fechados que abarcan desde ca. 7500-7200 a los 700-600 años calibrados AP (Goñi et al., 2014). El conjunto considerado en este trabajo se ubica entre los fechados de ca. 7500-7200 y 5600-5400 años calibrados AP. La muestra analizada (n artefactos formatizados: 100, n FNCRC: 35, n núcleos: 26, n desechos: 1090) incluye todos los artefactos formatizados y núcleos recuperados en la excavación, mientras que los desechos de talla fueron muestreados (se emplearon la totalidad de los provenientes de las cuadrículas 1, 2 y 4, pero no los de las cuadrículas 5 y 3) debido a su elevada frecuencia (más de 15.000 ejemplares, incluyendo los niveles del Holoceno tardío).

Gerasín 1 consiste en un alero rocoso conformado por el paredón basáltico que delimita la Meseta baja, en las cercanías de un mallín con agua y abundante vegetación. Se excavó $1 \mathrm{~m}^{2}$, en el cual se halló material lítico y óseo y se obtuvo un fechado de ca. 4100-3900 años calibrados AP (Goñi, et al. 2014). Los materiales procedentes del nivel que presenta este fechado son los considerados en este trabajo (n FNCRC: 1, n desechos: 10).

El sitio Patito (Píriz, 2004; Cassiodoro et al., 2014) es una dispersión superficial de materiales líticos ubicada en una serie de bermas vegetadas en la península de la Meseta baja. Los materiales se encuentran depositados entre los guijarros de las bermas, y presentan evidencias de rodado, redondeamiento de aristas y pátinas, así como lascados postdepositacionales, fruto de la acción del agua. A pesar de esto, la abundante presencia de lascas laminares y en materias primas alóctonas indica un origen antrópico para la mayor parte del conjunto (Píriz, 2004). Nuevas prospecciones en este sitio permitieron hallar en superficie bolas de boleadora y sobre la playa actual del lago, a unos $50 \mathrm{~m}$ de la concentración de artefactos líticos, abundantes restos óseos de guanaco con marcas de procesamiento, mezclados con escasos artefactos líticos. Estos materiales provenientes de superficie fueron fechados en 3000 y 3400 años radiocarbónicos AP, por lo que sería una cronología posible para al menos parte de las ocupaciones del sitio (Goñi et al. en preparación). La conformación de parte del sitio se habría dado al mismo tiempo que las bermas, las cuales se encuentran fechadas
(Piriz, 2004) entre los 5500-4500 y 2200 años calibrados AP (Goñi, et al. 2014; Stine y Stine, 1990). Debido a que luego de los 5000 años calibrados AP hubo una fuerte caída de los niveles del lago, que no volvieron a alcanzar los niveles superiores donde se encuentra parte del sitio, el conjunto se habría depositado en un período más cercano a esa fecha que a los 2200 años calibrados AP (Piriz 2004). En las cotas más altas y por encima de los niveles máximos del lago durante el Holoceno, la dispersión de materiales continúa, si bien los artefactos líticos no presentan evidencias de haber sido alterados por las aguas. Este conjunto se denomina "Sobre Patito" y debido a su incierta cronología, con características similares tanto a los conjuntos del Holoceno tardío como medio (Piriz 2004), no se considera en este trabajo. Los materiales analizados son los obtenidos en una recolección superficial sobre la totalidad del sitio, que abarcó aproximadamente 1575 $\mathrm{m}^{2}$ y comprende 45 artefactos formatizados, 10 FNCRC, 10 núcleos y 136 desechos.

Finalmente, Laguna del Cansancio es una dispersión superficial de materiales que abarcan $400 \mathrm{~m}$ de largo por $5 \mathrm{~m}$ de ancho, al reparo de un paredón rocoso y un conjunto de bloques junto a una laguna actualmente seca. Si bien el sitio no presenta materiales orgánicos fechables, el hallazgo de una punta apedunculada, asignable al Holoceno medio en base a la evidencia regional (Aschero 1987; Cassiodoro et al. 2020) permite considerar al sitio dentro de este período. Se recolectó y analizó la totalidad del material, consistente en artefactos líticos dispersos en una baja densidad ( $\mathrm{n}$ artefactos formatizados: 7, n FNCRC: 8 , n núcleos: 4, $\mathrm{n}$ desechos: 37 ).

\section{Resultados}

Se presenta a continuación la información correspondiente a los artefactos formatizados (tabla 1). Los fragmentos de instrumentos indiferenciados fueron excluidos de los conteos y constituyen proporciones variables en los tres sitios en que se encuentran presentes: ALG1 ( $n$ : 34, que representan 25,1\% del conjunto de artefactos formatizados), Manuk 1 ( $n$ : 4, el $25 \%$ ) y Patito ( $n$ : 2 , un $3,7 \%)$. Se destaca la ausencia de artefactos formatizados en dos conjuntos: Alero del León y Gerasín 1, probablemente debido a su pequeño tamaño de muestra.

Predominan los raspadores, seguidos de raederas, AFS y en menor proporción puntas de proyectil, bifaces, cuchillos y muescas, entre otros. Los diferentes sitios presentan una serie de similitudes, especialmente ALG1 y Patito, como su abundancia de raspadores (Figura 2.A), que llegan a una muy alta frecuencia en Patito, así como de raederas y AFS. En cambio, los sitios Laguna del Cansancio y Manuk 1 presentan algunas diferencias en su composición, como la mayor proporción de puntas de proyectil en el primero de éstos sitios y de cuchillos en el segundo. A pesar de ello, debe notarse que, por su 


\begin{tabular}{|c|c|c|c|c|c|}
\hline Tipo artefactual & ALG1 & Manuk 1 & Patito & $\begin{array}{c}\text { Laguna del } \\
\text { Cansancio }\end{array}$ & Total \\
\hline Raspador & $36,3(24)$ & $20(2)$ & $67,4(29)$ & $20(1)$ & $45,1(56)$ \\
\hline Raedera & $30,3(20)$ & $10(1)$ & $16,2(7)$ & 0 & $22,5(28)$ \\
\hline AFS & $22,7(15)$ & $10(1)$ & $6,9(3)$ & $20(1)$ & $16,1(20)$ \\
\hline Punta & $3,1(2)$ & $20(2)$ & 0 & $40(2)$ & $4,8(6)$ \\
\hline Cuchillo & $4,5(3)$ & $30(3)$ & 0 & 0 & $4,8(6)$ \\
\hline Bifaz & 0 & 0 & $4,6(2)$ & $20(1)$ & $2,4(3)$ \\
\hline Muesca & 0 & 0 & $4,6(2)$ & 0 & $1,8(2)$ \\
\hline PR Punta & $1,5(1)$ & 0 & 0 & 0 & $0,8(1)$ \\
\hline Bola & $1,5(1)$ & 0 & 0 & 0 & $0,8(1)$ \\
\hline Denticulado & 0 & $10(1)$ & 0 & 0 & $0,8(1)$ \\
\hline Total & $100(66)$ & $100(10)$ & $100(43)$ & $100(5)$ & $100(124)$ \\
\hline
\end{tabular}

Tabla 1: frecuencias y porcentajes de los conjuntos de artefactos formatizados del Holoceno medio. Entre paréntesis se indica el $n$. Referencias: PR Punta: preforma de punta de proyectil

Table 1: frequencies and percentages of Middle Holocene artifacts. The $n$ is indicated in parentheses. References: $P R$ Punta: projectile point preform.

pequeño tamaño de muestra, estas diferencias podrían ser el resultado de sesgos de muestreo. Las puntas incluyen un ejemplar lanceolado en Manuk 1 y uno triangular en Laguna del Cansancio, mientras que en el resto de los casos su morfología es indefinida debido a las fracturas (Figura 2.B). Aunque no han sido incluidos entre la muestra analizada, nuevas prospecciones han permitido hallar tres ejemplares de bolas de boleadora en el sitio Patito y sus alrededores, uno de las cuales presenta abrasión, por lo que posiblemente resulta contemporáneo a los otros materiales del sitio.
A

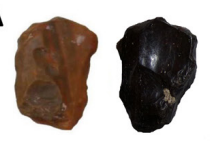

C
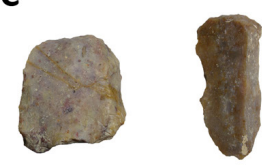

D

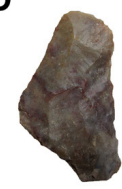

$\mathbf{E}$
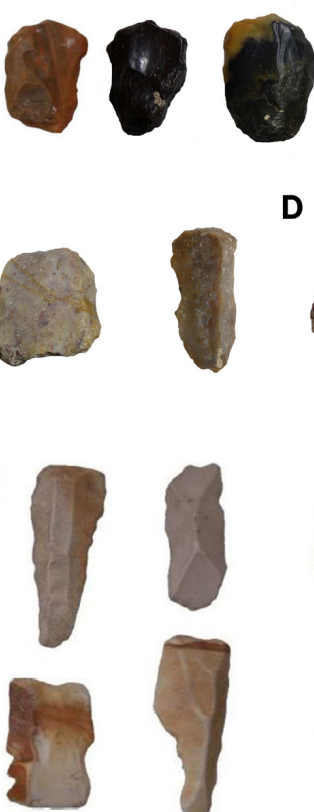

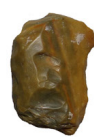

B
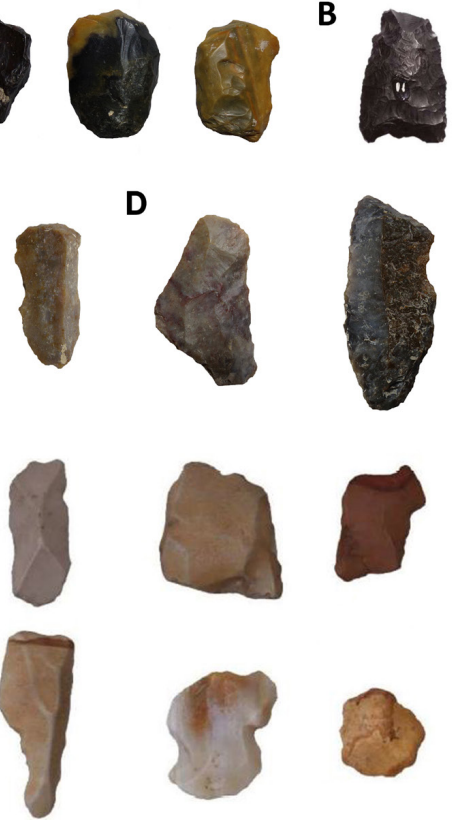
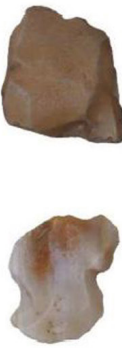
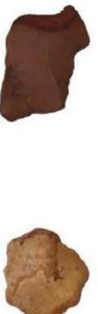
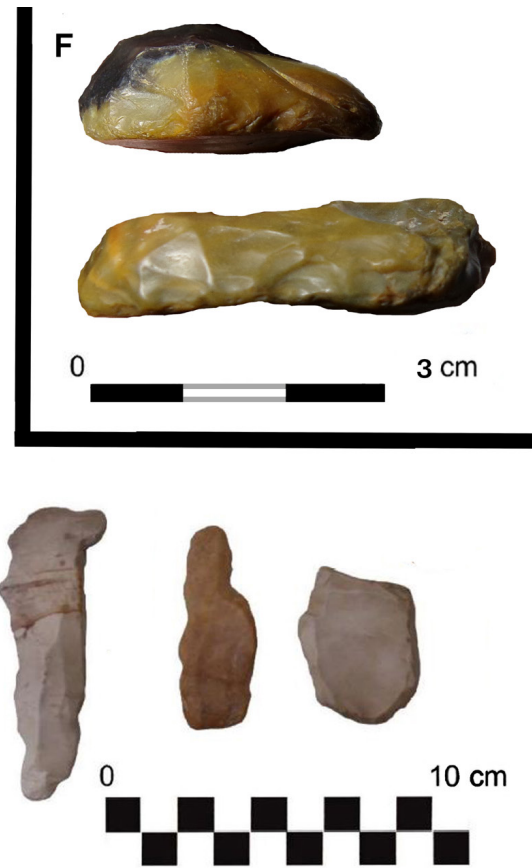

Figura 2: artefactos del Holoceno medio analizados. Referencias: A: raspadores del sitio Patito, B: punta de proyectil triangular del sitio Laguna del Cansancio, con su ápice fracturado, C: raspadores del sitio Manuk 1, D: cuchillos del sitio Manuk 1, E: desechos de talla alterados por el agua del sitio Patito, F: detalle de aristas abradidas y pulidas por el agua en raspadores del sitio Patito.

Figure 2: Middle Holocene artifacts analyzed. References: A: endscrapers from the Patito site, B: triangular projectile point from the Laguna del Cansancio site, with its tip fractured, C: endscrapers from the Manuk 1 site, D: knives from the Manuk 1 site, E: flakes and blades altered by the water from the Patito site, F: detail of eroded and water-polished edges on endscrapers from the Patito site. 


\begin{tabular}{|c|c|c|c|c|c|c|c|c|c|c|c|}
\hline \multirow{2}{*}{$\begin{array}{l}\text { Tipo de forma } \\
\text { base }\end{array}$} & \multicolumn{2}{|c|}{ ALG1 } & \multicolumn{2}{|c|}{ Manuk 1} & \multirow{2}{*}{$\begin{array}{c}\text { Gerasin } \\
1 \\
\text { FNCRC }\end{array}$} & \multicolumn{2}{|c|}{ Patito } & \multicolumn{2}{|c|}{$\begin{array}{l}\text { Laguna del } \\
\text { Cansancio }\end{array}$} & \multicolumn{2}{|c|}{ Total } \\
\hline & $\mathrm{AF}$ & FNCRC & $\mathrm{AF}$ & FNCRC & & $\mathrm{AF}$ & FNCRC & $\mathrm{AF}$ & FNCRC & $A F$ & FNCRC \\
\hline Ls primaria & $7(7)$ & $2,8(1)$ & 0 & 0 & 0 & 0 & 0 & 0 & 0 & $4,2(7)$ & $1,7(1)$ \\
\hline Ls secundaria & $2(2)$ & $2,8(1)$ & 0 & 0 & 0 & 0 & 0 & 0 & 0 & $1,2(2)$ & $1,7(1)$ \\
\hline $\begin{array}{l}\text { Ls de dorso } \\
\text { natural }\end{array}$ & 2 (2) & $5,7(2)$ & 0 & 0 & 0 & 0 & 0 & 0 & 12,5 (1) & $1,2(2)$ & $5,3(3)$ \\
\hline Ls angular & $\begin{array}{c}22 \\
(22)\end{array}$ & $34,2(12)$ & $\begin{array}{l}21,4 \\
(3)\end{array}$ & 0 & 0 & $\begin{array}{l}24,4 \\
(11)\end{array}$ & $20(2)$ & $\begin{array}{l}28,5 \\
(2)\end{array}$ & 37,5 (3) & $\begin{array}{l}22,8 \\
(38)\end{array}$ & $\begin{array}{l}30,3 \\
(17)\end{array}$ \\
\hline $\begin{array}{l}\text { Ls de } \\
\text { reactivación de } \\
\text { núcleo }\end{array}$ & 1 (1) & 0 & 0 & 0 & 0 & $\begin{array}{l}6,6 \\
(3)\end{array}$ & 0 & 0 & 0 & 2,4 (4) & 0 \\
\hline $\begin{array}{l}\text { Ls de dorso } \\
\text { preparado }\end{array}$ & 0 & 0 & $\begin{array}{l}14,2 \\
(2)\end{array}$ & 0 & 0 & 0 & 0 & 0 & 0 & $1,2(2)$ & 0 \\
\hline $\begin{array}{c}\text { Ls de } \\
\text { adelgazamiento } \\
\text { bifacial }\end{array}$ & 1 (1) & 0 & 0 & 0 & 0 & 0 & 0 & 0 & 0 & $0,6(1)$ & 0 \\
\hline $\begin{array}{l}\text { Ls de } \\
\text { reactivación de } \\
\text { filos }\end{array}$ & 0 & 0 & 0 & 0 & 0 & 0 & $10(1)$ & 0 & 0 & 0 & $1,7(1)$ \\
\hline Ls de arista & 4 (4) & $17,1(6)$ & 0 & 0 & 0 & $\begin{array}{l}4,4 \\
(2)\end{array}$ & $10(1)$ & 0 & 0 & $3,6(6)$ & $\begin{array}{l}12,5 \\
(7)\end{array}$ \\
\hline Hoja & $5(5)$ & $11,4(4)$ & 0 & 0 & $100(1)$ & $\begin{array}{l}24,4 \\
(11)\end{array}$ & 40 (4) & 0 & $25(2)$ & 9,6 (16) & $\begin{array}{l}19,6 \\
(11)\end{array}$ \\
\hline Lámina & $3(3)$ & $8,5(3)$ & $\begin{array}{l}14,2 \\
(2)\end{array}$ & 0 & 0 & $\begin{array}{l}6,6 \\
(3)\end{array}$ & $20(2)$ & 0 & 0 & 4,8 (8) & $8,9(5)$ \\
\hline INDIF. & $\begin{array}{r}53 \\
(53)\end{array}$ & $17,1(6)$ & $\begin{array}{l}35,7 \\
(5)\end{array}$ & $100(2)$ & 0 & $\begin{array}{l}33,3 \\
(15)\end{array}$ & 0 & $\begin{array}{l}71,4 \\
(5)\end{array}$ & $25(2)$ & $46,9(78)$ & $\begin{array}{l}17,8 \\
(10)\end{array}$ \\
\hline Total & $\begin{array}{c}100 \\
(100)\end{array}$ & $100(35)$ & $\begin{array}{l}100 \\
(14)\end{array}$ & $100(2)$ & $100(1)$ & $\begin{array}{l}100 \\
(45)\end{array}$ & $100(10)$ & $\begin{array}{l}100 \\
(7)\end{array}$ & $100(8)$ & $\begin{array}{c}100 \\
(166)\end{array}$ & $\begin{array}{l}100 \\
(56)\end{array}$ \\
\hline
\end{tabular}

Tabla 2: porcentajes y frecuencias de formas base entre los artefactos formatizados y FNCRC. Referencias: Ls: lasca, INDIF.: forma base indiferenciada. Entre paréntesis se indica el $n$.

Table 2: percentages and frequencies of blanks among formal artifacts and FNCRC. References: Ls: flake, INDIF.: indeterminate blank. The $n$ is indicated in parentheses.

Entre los artefactos formatizados la mayor parte de la muestra se concentra en un conjunto pequeño de grupos tipológicos, ya que las tres categorías más representadas (raspadores, AFS y raederas) agrupan al $83,7 \%$ de la muestra. Si se analiza la relación entre el tamaño de las muestras y la cantidad de tipos representados, el resultado indica una relación moderada $(r: 0,67)$ pero no significativa ( $p: 0,32$ ), posiblemente como resultado de que los conjuntos son pocos y en su mayoría de pequeño tamaño.

La presencia de FNCRC en las muestras es elevada ( $\mathrm{n}$ : 56) y generalmente supera en frecuencia a los artefactos formatizados más representados, con la excepción del conjunto Patito. Como se mencionó previamente, este sitio posiblemente tenga subrepresentada dicha categoría fruto de sus procesos de formación. De acuerdo a esto, puede considerarse que los artefactos no formatizados habrían sido más frecuentemente utilizados en los conjuntos que cualquier tipo de artefacto formatizado.

Se evaluaron los tipos de formas base entre los artefactos formatizados y FNCRC, con el objetivo de considerar la distribución de actividades de talla entre los conjuntos (tabla 2). La tabla incluye los fragmentos de artefactos formatizados indiferenciados. 


\begin{tabular}{|c|c|c|c|c|c|c|c|c|c|c|c|}
\hline $\begin{array}{c}\text { Materia } \\
\text { prima }\end{array}$ & \multicolumn{2}{|c|}{ ALG1 } & \multicolumn{2}{|c|}{ Manuk 1 } & $\begin{array}{c}\text { Gerasin } \\
1\end{array}$ & \multicolumn{2}{|c|}{ Patito } & \multicolumn{2}{|c|}{ Laguna del Cansancio } & \multicolumn{2}{c|}{ Total } \\
\cline { 2 - 12 } & AF & FNCRC & AF & FNCRC & FNCRC & AF & FNCRC & AF & FNCRC & AF & FNCRC \\
\hline Limolita & $\begin{array}{c}47 \\
(47)\end{array}$ & $\begin{array}{c}54,2 \\
(19)\end{array}$ & $\begin{array}{c}21,4 \\
(3)\end{array}$ & $50(1)$ & 0 & $\begin{array}{c}22,2 \\
(10)\end{array}$ & $40(4)$ & 0 & $37,5(3)$ & $\begin{array}{c}36,1 \\
(60)\end{array}$ & $\begin{array}{c}48,2 \\
(27)\end{array}$ \\
\hline $\begin{array}{c}\text { Rocas } \\
\text { siliceas }\end{array}$ & $\begin{array}{c}23 \\
(23)\end{array}$ & $\begin{array}{c}28,5 \\
(10)\end{array}$ & $\begin{array}{c}35,7 \\
(5)\end{array}$ & $50(1)$ & 0 & $\begin{array}{c}71,1 \\
(32)\end{array}$ & $30(3)$ & $14,2(1)$ & $37,5(3)$ & $\begin{array}{c}36,7 \\
(61)\end{array}$ & $\begin{array}{c}30,3 \\
(17)\end{array}$ \\
\hline Obsidiana & $\begin{array}{c}12 \\
(12)\end{array}$ & 0 & $\begin{array}{c}28,5 \\
(4)\end{array}$ & 0 & 0 & 0 & $10(1)$ & $\begin{array}{c}42,8 \\
(3)\end{array}$ & 0 & $\begin{array}{c}11,4 \\
(19)\end{array}$ & $1,7(1)$ \\
\hline Otras & $7(7)$ & $5,7(2)$ & $\begin{array}{c}14,2 \\
(2)\end{array}$ & 0 & $100(1)$ & $4,4(2)$ & $20(2)$ & $14,2(1)$ & $25(2)$ & $\begin{array}{c}7,2 \\
(12)\end{array}$ & $12,5(7)$ \\
\hline Basalto & $7(7)$ & $11,4(4)$ & 0 & 0 & 0 & $2,2(1)$ & 0 & $28,5(2)$ & 0 & $\begin{array}{c}6,1 \\
(10)\end{array}$ & $7,1(4)$ \\
\hline Xilópalo & $4(4)$ & 0 & 0 & 0 & 0 & 0 & 0 & 0 & 0 & $\begin{array}{c}2,4 \\
(4)\end{array}$ & 0 \\
\hline Total & $\begin{array}{c}100 \\
(100)\end{array}$ & $\begin{array}{c}100 \\
(35)\end{array}$ & $\begin{array}{c}100 \\
(14)\end{array}$ & $100(2)$ & $100(1)$ & $\begin{array}{c}100 \\
(45)\end{array}$ & $100(10)$ & $100(7)$ & $100(8)$ & $\begin{array}{c}100 \\
(166)\end{array}$ & $100(56)$ \\
\hline
\end{tabular}

Tabla 3: porcentajes de materias primas en artefactos formatizados y FNCRC. Entre paréntesis se indica el $n$.

Table 3: percentages of raw materials in formal artifacts and FNCRC. The $n$ is indicated in parentheses.

Entre las formas base predominan las lascas internas angulares, seguidas por las hojas y láminas y una baja frecuencia de desechos corticales (lascas primarias, secundarias y de dorso natural). Se destaca una mayor abundancia de hojas, láminas y lascas de arista entre los FNCRC en la mayor parte de los sitios (véase también Agnolin 2020). Asimismo, hay una elevada frecuencia de hojas en Patito, mientras que en el resto de los conjuntos dominan las lascas angulares.

El uso de las materias primas se presenta en la tabla 3. En la misma se consideran los FNCRC y artefactos formatizados, incluyendo los fragmentos indiferenciados. Las materias primas más utilizadas fueron la limolita y las rocas silíceas, seguidas por la obsidiana y una variedad de rocas menos representadas en el conjunto. Es notable la baja frecuencia de basalto, el cual se encuentra disponible abundantemente en las cercanías de todos los sitios analizados. Todos los artefactos en esta materia prima son de variedades de grano fino, a excepción del fragmento de bola de boleadora que está elaborado en un basalto vesicular de grano grueso. Existen diferencias considerables entre las muestras, destacándose el uso de la limolita en ALG1, la cual se encuentra naturalmente disponible a $300 \mathrm{mt}$ del sitio. En el resto de los conjuntos predominan las rocas silíceas y la limolita constituye una parte importante de los mismos. Se destaca que a pesar de que el sitio Patito se encuentra a escasos $200 \mathrm{mt}$ de la fuente de una roca clasificable como limolita, la misma ha sido menos utilizada que las rocas silíceas, también disponibles en la inmediata vecindad (Agnolin et al. 2018). Asimismo, la obsidiana presenta frecuencias moderadas en algunos sitios, a pesar de que estos se encuentran a más de $90 \mathrm{~km}$ de la fuente de dicha roca. Por otra parte, si consideramos la diferencia entre artefactos formatizados y FNCRC, se destaca el mayor uso de obsidiana entre los artefactos formatizados, mientras que la limolita tiene una mayor participación entre los FNCRC. En términos generales puede considerarse que hay un fuerte uso de las rocas disponibles en la cuenca.

Con el objeto de analizar en mayor detalle el uso de las materias primas, se presenta la información correspondiente a los diferentes tipos de artefactos formatizados (tabla 4). En términos generales, se destaca el predominio de diferentes rocas entre los distintos tipos de artefactos, de modo que los raspadores fueron preferentemente elaborados en rocas silíceas, las raederas y AFS en limolita y las puntas de proyectil exclusivamente en obsidiana. Otras rocas se encuentran menos representadas, aunque cabe señalar el uso del basalto en la confección de raederas. Si bien es un tipo artefactual poco frecuente, se destaca que la confección de bifaces, al contrario de la de puntas, aparece en diversas rocas. Esta información, combinada con la de la tabla 3, permite sugerir que se da una 


\begin{tabular}{|c|c|c|c|c|c|c|c|}
\hline $\begin{array}{c}\text { Tipo } \\
\text { artefactual }\end{array}$ & Limolita & $\begin{array}{c}\text { Rocas } \\
\text { siliceas }\end{array}$ & Obsidiana & Basalto & Otras & Xilópalo & Total \\
\hline Raspador & $13,7(8)$ & $63,7(37)$ & $8,6(5)$ & $1,7(1)$ & $8,6(5)$ & $3,4(2)$ & $100(58)$ \\
\hline Raedera & $50(14)$ & $21,4(6)$ & $3,5(1)$ & $14,2(4)$ & $10,7(3)$ & 0 & $100(28)$ \\
\hline AFS & $80(16)$ & $5(1)$ & 0 & $5(1)$ & $5(1)$ & $5(1)$ & $100(20)$ \\
\hline Punta & 0 & 0 & $100(6)$ & 0 & 0 & 0 & $100(6)$ \\
\hline Cuchillo & $16,6(1)$ & $50(3)$ & $16,6(1)$ & 0 & 0 & $16,6(1)$ & $100(6)$ \\
\hline Bifaz & $33,3(1)$ & $33,3(1)$ & 0 & $33,3(1)$ & 0 & 0 & $100(3)$ \\
\hline Muesca & $100(2)$ & 0 & 0 & 0 & 0 & 0 & $100(2)$ \\
\hline $\begin{array}{c}\text { PR Punta } \\
\text { Bola }\end{array}$ & 0 & 0 & $100(1)$ & 0 & 0 & 0 & $100(1)$ \\
\hline $\begin{array}{c}\text { Denticulado } \\
\text { artefactos } \\
\text { formatizados }\end{array}$ & $100(1)$ & 0 & 0 & 0 & 0 & 0 & $100(1)$ \\
\hline FAF & $41,4(17)$ & $34,1(14)$ & $12,1(5)$ & $4,8(2)$ & $7,3(3)$ & 0 & $100(41)$ \\
\hline Total & $36,7(61)$ & $11,4(19)$ & $6,1(10)$ & $7,2(12)$ & $2,4(4)$ & $100(166)$ \\
\hline
\end{tabular}

Tabla 4: porcentajes de materias primas en artefactos formatizados. Referencias: PR Punta: preforma de punta de proyectil, FAF: fragmento de artefacto formatizado. Entre paréntesis se indica el $n$.

Table 4: percentages of raw materials in formal artifacts. References: PR Punta: projectile point preform, FAF: formal artifact fragment. The $n$ is indicated in parentheses.

selectividad en el uso de rocas para la elaboración de los diferentes tipos artefactuales, si bien en casi todos los casos se recurrió a rocas locales o inmediatamente disponibles.

Los núcleos componen una parte menor de la muestra y su frecuencia con relación a la de artefactos formatizados varía. De este modo, en Manuk 1 hay 0,14 núcleos por cada artefacto formatizado, en Patito 0,22, en ALG1 0,26 y en Laguna del Cansancio 0,57. Manuk 1 también presenta abundantes evidencias de talla, especialmente núcleos de limolita en su talud, sin embargo, los mismos presentan una frecuencia similar $(0,18$ núcleos por cada artefacto formatizado) a la hallada en estratigrafía (Agnolin, 2019). De este modo, puede considerarse que habría un mayor peso de las actividades de obtención de formas base en el conjunto de Laguna del Cansancio, mientras que en Manuk 1 estas habrían sido menos frecuentes y en Patito ocuparían un lugar intermedio. En los casos de Gerasín 1 y Alero del León, la ausencia de núcleos estaría vinculada al pequeño tamaño de las muestras. En ALG1, la presencia de núcleos y abundantes desechos de talla en su talud, de cronología incierta, dificulta definir claramente la importancia de esta actividad durante el Holoceno medio.

Los núcleos presentan en casi todos los casos extracciones de lascas, a excepción de un ejemplar de limolita, poliédrico y con extracciones laminares, proveniente de ALG1. En las materias primas de los núcleos predomina la limolita (tabla 5), seguida por las rocas silíceas y en menor frecuencia un conjunto de otras rocas. La limolita y las rocas silíceas están bien representadas en casi todos los sitios y la primera de ellas es especialmente abundante en

\begin{tabular}{|c|c|c|c|c|c|c|}
\hline Materia prima & ALG1 & Manuk 1 & Patito & $\begin{array}{c}\text { Laguna del } \\
\text { Cansancio }\end{array}$ & N Total & $\%$ Total \\
\hline Limolita & 17 & 1 & 3 & 0 & 21 & 50 \\
\hline Rocas siliceas & 5 & 0 & 4 & 3 & 12 & 28,5 \\
\hline Obsidiana & 2 & 0 & 1 & 1 & 4 & 9,5 \\
\hline Xilópalo & 2 & 1 & 0 & 0 & 3 & 7,1 \\
\hline Otras & 0 & 0 & 2 & 0 & 2 & 4,7 \\
\hline Total & 26 & 2 & 10 & 4 & 42 & 100 \\
\hline
\end{tabular}

Tabla 5: frecuencias y porcentajes de materias primas en núcleos.

Table 5: frequencies and percentages of raw materials in cores. 
A. M. Agnolin | Revista del Museo de Antropología 14 (3): 133-150 | 2021

DOI: http://doi.org/10.31048/1852.4826.v14.n3.33352

\begin{tabular}{|c|c|c|c|c|c|c|c|}
\hline $\begin{array}{c}\text { Materia } \\
\text { prima }\end{array}$ & ALG1 & Manuk 1 & $\begin{array}{c}\text { Alero del } \\
\text { León }\end{array}$ & Gerasin 1 & Patito & $\begin{array}{c}\text { Laguna del } \\
\text { Cansancio }\end{array}$ & Total \\
\hline Limolita & $59,5(228)$ & $11,2(8)$ & $26,6(4)$ & 0 & $67,5(42)$ & $20(4)$ & $51,3(286)$ \\
\hline $\begin{array}{c}\text { Rocas } \\
\text { siliceas }\end{array}$ & $18,5(71)$ & $25,3(18)$ & $40(6)$ & $50(1)$ & $29,7(19)$ & $40(8)$ & $22,1(123)$ \\
\hline Basalto & $7,1(27)$ & $28,1(20)$ & 0 & $50(1)$ & $5,4(4)$ & $15(3)$ & $9,8(55)$ \\
\hline Xilópalo & $0,2(1)$ & 0 & 0 & 0 & 0 & 0 & $0,1(1)$ \\
\hline Obsidiana & $10,4(40)$ & $26,7(19)$ & $13,3(2)$ & 0 & $4,1(1)$ & $15(3)$ & $11,6(65)$ \\
\hline Otras & $3,9(15)$ & $8,4(6)$ & $20(3)$ & 0 & $1,3(1)$ & $10(2)$ & $4,8(27)$ \\
\hline Total & $100(382)$ & $100(71)$ & $100(15)$ & $100(2)$ & $100(67)$ & $100(20)$ & $100(557)$ \\
\hline
\end{tabular}

Tabla 6: materias primas de desechos de talla enteros y fracturados con talón. Entre paréntesis se indica el $\mathrm{n}$.

Table 6: raw materials from whole flakes and flakes with plataform. The $n$ is indicated in parentheses.

ALG1. La obsidiana, a pesar de ser menos frecuente, está representada en tres de los cuatro sitios que presentan núcleos. Finalmente, se destaca la ausencia de núcleos de basalto, a pesar de que esta roca se encuentra representada entre otras clases de artefactos. En términos generales, las rocas explotadas son principalmente las inmediatamente disponibles en torno a los sitios, si bien la ausencia del basalto en el conjunto de núcleos resulta una excepción a este patrón.

Finalmente, en el caso de los desechos de talla, estos son la categoría más representada en todos los sitios, especialmente en ALG1. Las rocas más representadas entre éstos son la limolita, seguida por las rocas silíceas y en menor frecuencia la obsidiana y un conjunto de rocas diversas agrupadas en la categoría "Otras".

Los diferentes sitios poseen una composición disímil de materias primas, ya que en ALG1 y Patito predomina la limolita, en Manuk 1 lo hace el basalto y en el resto de los sitios las rocas silíceas (tabla 6). La obsidiana, por otra parte, presenta frecuencias elevadas en Manuk 1. En el caso del basalto, hay que señalar que se compone en su mayoría de variedades de grano fino, a excepción de un desecho de ALG1 y nueve desechos en Manuk 1 de grano grueso. La utilización de esta última variedad estaría vinculada a la manufactura de bolas de boleadora, ya que son los únicos artefactos formatizados en esta roca conocidos en la cuenca para el Holoceno medio (Agnolin 2019). En términos generales, puede considerarse que hay una preferencia por la explotación de las rocas inmediatamente disponibles en torno a los sitios, si bien la elevada frecuencia de obsidiana en Manuk 1 resulta una excepción.

Finalmente, se analizó el tipo de desechos de talla presentes, con el objeto de discutir la distribución de actividades de talla entre los diferentes conjuntos (tabla 7). Los tipos más representados consisten en lascas internas angulares, seguidas por lascas corticales y una baja frecuencia de hojas y lascas de retoque de instrumentos. Se destaca la elevada presencia de hojas y láminas en Patito y Laguna del Cansancio, así como de lascas de retoques de instrumentos en Alero del León. En términos generales, puede considerarse que los conjuntos muestran actividades de obtención de formas base, con una menor proporción de actividades de talla inicial (lascas corticales) y formatización de instrumentos. En el caso de Patito y posiblemente en el de Laguna del Cansancio, la elevada proporción de láminas y hojas apuntaría a la manufactura sistemática de formas base alargadas, si bien la ausencia de núcleos laminares señala la posibilidad de su transporte por fuera de los sitios. En Patito, esto coincide con la elevada representación de estos soportes entre los artefactos formatizados y FNCRC. En el caso de Alero del León y Gerasín 1 las muestras presentan un tamaño pequeño y son insuficientes como para evaluar claramente las actividades de talla, si bien al menos en el primero de los sitios se habrían reactivado artefactos formatizados y posiblemente formatizado o extraído formas base.

La comparación de la composición de las materias primas entre los desechos de talla, núcleos, artefactos formatizados y FNCRC, muestra similitudes en términos generales. Sin embargo, las rocas silíceas se encuentran mejor representadas entre los artefactos formatizados y FNCRC que entre los desechos de talla, mientras que el basalto, a pesar de hallarse bien representado entre los artefactos formatizados y desechos de talla, está completamente ausente de los núcleos. Se puede considerar que en cada sitio predomina el uso de las rocas inmediatamente disponibles.

\section{Discusión}

El proceso de poblamiento de la cuenca del lago Cardiel transcurrió durante un extenso período de variaciones climático/ambientales, que incluyeron cambios en la humedad a escala regional. Durante gran parte del Holoceno medio, el paisaje de la cuenca se habría caracterizado por la mayor disponibilidad de agua y 


\begin{tabular}{|c|c|c|c|c|c|c|c|}
\hline Tipo de desecho & ALG1 & Manuk 1 & $\begin{array}{l}\text { Alero del } \\
\text { León }\end{array}$ & Gerasín 1 & Patito & $\begin{array}{l}\text { Laguna del } \\
\text { Cansancio }\end{array}$ & Total \\
\hline Ls primaria & $3,1(12)$ & $1,4(1)$ & 0 & 0 & $1,4(1)$ & $5(1)$ & $2,6(15)$ \\
\hline Ls secundaria & $3,9(15)$ & $4,2(3)$ & 0 & 0 & $1,4(1)$ & 0 & 3,4 (19) \\
\hline Ls de dorso natural & $0,7(3)$ & 0 & $6,6(1)$ & 0 & $2,9(2)$ & $5(1)$ & $1,2(7)$ \\
\hline Ls angular & $60,4(231)$ & $73,2(52)$ & $53,3(8)$ & $100(2)$ & $52,2(35)$ & $40(8)$ & $60,4(336)$ \\
\hline $\begin{array}{c}\text { Ls de reactivación de } \\
\text { núcleo }\end{array}$ & $0,5(2)$ & $2,8(2)$ & $6,6(1)$ & 0 & $1,4(1)$ & 0 & $1,1(6)$ \\
\hline Ls de dorso preparado & $1,1(4)$ & 0 & 0 & 0 & 0 & 0 & $0,7(4)$ \\
\hline $\begin{array}{c}\text { Ls de adelgazamiento } \\
\text { bifacial }\end{array}$ & $0,7(3)$ & $2,8(2)$ & 0 & 0 & 0 & 0 & $0,8(5)$ \\
\hline $\begin{array}{l}\text { Ls de retoque de } \\
\text { instrumento }\end{array}$ & $4,7(18)$ & 0 & $26,6(4)$ & 0 & 0 & 0 & $3,9(22)$ \\
\hline Plana & $2,6(10)$ & $4,2(3)$ & $6,6(1)$ & 0 & 0 & 0 & $2,5(14)$ \\
\hline Ls de arista & $3,4(13)$ & $2,8(2)$ & 0 & 0 & $7,4(5)$ & $10(2)$ & $3,9(22)$ \\
\hline Hoja & $1,3(5)$ & 0 & 0 & 0 & $22,3(15)$ & $15(3)$ & $4,1(23)$ \\
\hline Lámina & $1,3(5)$ & $1,4(1)$ & 0 & 0 & $7,4(5)$ & $25(5)$ & $2,8(16)$ \\
\hline INDIF. & $15,9(61)$ & $7,1(5)$ & 0 & 0 & $2,9(2)$ & 0 & $12,1(67)$ \\
\hline Total & $100(382)$ & $100(71)$ & $100(15)$ & $100(2)$ & $100(67)$ & $100(20)$ & $100(556)$ \\
\hline
\end{tabular}

Tabla 7: porcentajes de tipos de desechos de talla. Referencias: Ls: lasca, INDIF.: desecho indiferenciado. Entre paréntesis se indica el $n$.

Table 7: percentages of types of flakes. References: Ls: flake, INDIF.: indeterminate debitage. The $n$ is indicated in parentheses.

una significativa homogeneidad en la distribución de recursos, si bien con variaciones a lo largo del tiempo. La tendencia a niveles elevados del lago durante dicho período mantuvo inundados espacios como la actual desembocadura de los ríos Cardiel y Bayo y parte de los Médanos del sur y este. Dichas condiciones estructuraron el paisaje arqueológico regional.

La dinámica de ocupación del lago Cardiel durante el Holoceno medio posee características peculiares en el contexto macrorregional, compatibles con las de los espacios ubicados más al sur. En este sentido, la cuenca posee una de las mayores concentraciones de evidencia arqueológica del Holoceno medio conocida a nivel regional, junto con el PNPM. En contraste, las mesetas del Strobel, Guitarra y Asador, Cerro Pampa y la cuenca del Lago Salitroso poseen escasos conjuntos de esta cronología o su registro se limita a puntas de proyectil apedunculadas en superficie (Cassiodoro, et al. 2013). En espacios ubicados más al norte, como la cuenca del lago Pueyrredón o el área de Paso Roballos también se registran ocupaciones de este período, si bien en el primero de los casos, las mismas aparecen como poco intensas (Mengoni Goñalons, 2019, Sacchi et al., 2016). Por otra parte, en el caso de los lagos Tar y San Martín, situados al sur del Cardiel, hay una señal algo mayor para este período (Belardi et al., 2013), que incluye evidencias del uso de la limolita del lago Cardiel en estas cuencas (Belardi et al., 2015). Dichas características sugieren la posibilidad de contactos entre ambos espacios y una dinámica de poblamiento con puntos en común.

Las primeras ocupaciones de la cuenca se encuentran fechadas en torno a los 7100-7600 años calibrados AP (Goñi y Belardi, 2014). Estos fechados señalan una ocupación inicial de la región desfasada con respecto a áreas vecinas como el lago Pueyrredón, la Altiplanicie central, la cuenca del Río Pinturas, el PNPM, o el lago San Martín, que se encontraban ya colonizados desde el Pleistoceno final o el Holoceno temprano (Aschero, et al. 2005; Belardi et al., 2013; Gradin et al., 1987; Mosquera, 2018; Sacchi et al., 2016). En trabajos previos se ha considerado que este desfasaje se debió a una combinación entre una baja demografía y la existencia de dificultades a la circulación de los grupos 
humanos (Agnolin, 2019; Goñi y Belardi, 2014). Más allá de las causas específicas de este proceso, es importante señalar que las ocupaciones analizadas en este trabajo se habrían realizado en un espacio previamente desconocido, muy posiblemente por parte de grupos pequeños que explotarían un espacio de grandes dimensiones. Estos procesos, que implican la existencia de procesos de exploración y colonización disímiles a nivel regional, coinciden con lo planteado en los modelos de poblamiento de Patagonia (Borrero 1989-1990).

Las ocupaciones del Holoceno medio se dieron en un espacio restringido, en un contexto en el que amplios sectores de la cuenca se encontraban debajo de las aguas. De acuerdo a esto, las ocupaciones tienen una distribución limitada, concentrándose en sectores altos que no fueron afectados por el ascenso de los niveles del lago. De este modo, tanto los sitios fechados, como los hallazgos aislados de puntas de proyectil apedunculadas (Cassiodoro, et al. 2020), se distribuyen únicamente en los sectores de Cañadones, Meseta baja y Pie de meseta. La única excepción es una punta de proyectil hallada en los Médanos del sur y situada a una altitud superior a la alcanzada por las aguas durante el Holoceno medio (Cassiodoro et al., 2020). Dentro de esta limitada distribución, el registro se encuentra concentrado en el sector sur de los Cañadones, en una pequeña área de menos de $30 \mathrm{~km}^{2}$ en el que se encuentran Manuk 1, Alero del León y 10 de las 15 puntas apedunculadas halladas en superficie en la cuenca (Cassiodoro et al., 2020).

En cuanto a la funcionalidad de los conjuntos, puede señalarse a los mismos como sitios de actividades limitadas (Borrero, 1987; Wilmsen, 1970), en los cuales se llevaron a cabo tareas de procesamiento. La interpretación se apoya en la escasa variabilidad de los conjuntos, en los que predomina un rango muy estrecho de artefactos formatizados, algo esperable en esta clase de sitios (Binford, 1980; Gould, 1980; Thomas, 1983). Esta asignación coincide con la proveniente del registro zooarqueológico que muestran el aprovechamiento casi exclusivo del guanaco, siempre en bajos números (Rindel y Bourlot, 2014). La ausencia en los sitios de otros tipos de evidencias (entierros, estructuras como pozos o basureros) apoya la propuesta acerca de la realización de un acotado rango de actividades.

En cuanto a la tecnología presente, la misma apunta a una ocupación del espacio con características similares en los diferentes sectores, en la cual los distintos sitios habrían tenido una similar funcionalidad. De este modo, la tecnología se compone únicamente de artefactos líticos, con conjuntos de instrumentos conformados principalmente por lascas, láminas u hojas con retoques o rastros de uso (AFS, FNCRC) y raspadores. Por otra parte, la tecnología bifacial es escasa y consiste únicamente en puntas apedunculadas y bifaces, mientras que se encuentra totalmente ausente el instrumental de molienda como molinos, manos o litos modificados por uso, algo que contrasta con su abundancia durante el Holoceno tardío (Cassiodoro et al. 2014; Goñi 2010). La principal diferencia entre conjuntos se encuentra en la mayor frecuencia de raspadores del sitio Patito (posible fruto de procesos de formación). Si nuevamente comparamos con las evidencias provenientes del Holoceno tardío, vemos que las mismas presentan una mayor variabilidad y heterogeneidad en su distribución, así como una mayor riqueza y una mayor frecuencia de artefactos de manufactura compleja como bolas, puntas y bifaces, independientemente de su tamaño de muestra (Agnolin 2019, Agnolin et al. 2019, Cassiodoro et al. 2014).

En resumen, la tecnología de la cuenca durante el Holoceno medio posee un perfil dominado por artefactos de procesamiento con una escasa inversión de energía (Andrefsky, 1994; Escola, 2004) en términos de su formatización y obtención de materias primas, en su gran mayoría instrumentos unifaciales sobre lascas $u$ hojas confeccionados mediante retoque sobre rocas inmediatamente disponibles. La mayor variabilidad dentro de este panorama se da en la desigual frecuencia del uso de hojas como forma base en los diferentes conjuntos. Si bien la producción de estos soportes podría involucrar una mayor inversión de energía en la manufactura de artefactos, lo cierto es que también son fácilmente elaborados mediante la percusión directa en una variedad de tipos de núcleos, los cuales no requieren de una estandarización en su morfología ni te técnicas de manufactura complejas (Nami y Bellelli, 1994). La presencia de extracciones laminares en un núcleo poliédrico de ALG1 apoya este planteo.

Las actividades de talla también muestran una distribución similar en el espacio, apuntando a la realización de una variedad de actividades en los sitios. En todos los conjuntos el predominio de desechos internos señala actividades de formatización de artefactos. Asimismo, todos los conjuntos con muestras amplias presentan núcleos, algo que apuntaría a la extracción de soportes. En este último caso, el conjunto de Laguna del Cansancio señalaría una mayor presencia de actividades de extracción de formas base, a juzgar por la abundancia de núcleos. Por otra parte, en ALG1 (Agnolin, 2020) y Manuk 1 (Cassiodoro et al., 2014) habría habido intensas actividades de talla en limolita en base al volumen de desechos y núcleos descartados, si bien estas actividades habrían sido llevadas a cabo de manera complementaria con otras de procesamiento de recursos.

Dentro de las actividades de talla, sin embargo, existe una diferencia marcada en la extracción y uso de formas base. De este modo, mientras que en los sitios de Meseta baja y Pie de meseta hay abundantes evidencias 
de la manufactura y uso de soportes laminares, en los conjuntos de Cañadones estos soportes resultan escasos. Las variaciones apuntarían al desarrollo de estrategias de manufactura y uso de artefactos diferenciadas en el espacio, a pesar de que las distintas formas base fueron empleadas para la confección de los mismos tipos artefactuales. En este sentido, tanto hojas como lascas fueron empleadas principalmente para la confección de raspadores, raederas y FNCRC (Agnolin, 2019, 2020). Las causas de estas diferencias podrían explicarse por variaciones en la demanda de artefactos. De este modo, las láminas y hojas brindan una forma estandarizada que puede utilizarse para un rápido recambio de instrumentos, especialmente útil si éstos se encuentran enmangados y se requieren piezas intercambiables de dimensiones predeterminadas (Hayden et al., 1996; Bar-Yosef y Kuhn, 1999). Estas condiciones tienden a darse en contextos en los cuales hay que procesar grandes volúmenes de materiales en períodos breves de tiempo (Hayden et al., 1996). Este podría ser el caso en los conjuntos de Meseta baja y Pie de meseta, los cuales se encuentran en torno a un área de concentración estacional de guanacos. Si bien es una hipótesis a explorar a futuro, es posible que la caza de guanacos en la Meseta baja y sus bordes diese como resultado el procesamiento de varias carcasas en un período acotado de tiempo y por ende la necesidad de contar con una abundante cantidad de artefactos de similares características y elaborados de antemano para procesarlos.

El uso de las materias primas se caracteriza por la utilización de las rocas locales dentro de la cuenca, principalmente la limolita y las rocas silíceas. Asimismo, en cada sitio tiende a predominar el uso de rocas inmediatamente disponibles. Dentro de estas tendencias generales, hay una preferencia por las rocas silíceas para la confección de artefactos formatizados, a excepción de ALG1, en el que primó el uso de los abundantes depósitos de limolita inmediatamente disponibles. La única roca que implicaría el abastecimiento de materias primas en otros espacios por fuera del Cardiel es la obsidiana de Pampa del Asador, presente en baja frecuencia en todas las geoformas ocupadas durante el Holoceno medio y casi todos los sitios. Por otra parte, dentro de la tendencia al uso de las rocas inmediatamente disponibles, hay una selección de diferentes materias primas para los distintos tipos artefactuales. De este modo, los raspadores tienden a ser de rocas silíceas, las raederas y AFS de limolita y las puntas de proyectil de obsidiana. El uso de esta última roca en la confección de puntas explicaría su mayor frecuencia en Laguna del Cansancio y Manuk 1, ya que son los conjuntos con la mayor abundancia de puntas de proyectil. Finalmente, se destaca que, a pesar de esta preferencia por el uso de rocas locales, el basalto ha tenido escasa utilización. Estudios previos han señalado que esta última roca fue utilizada preferentemente para la confección de raederas, cuchillos y FNCRC tanto durante el Holoceno medio como tardío (Agnolin 2019,
2020, Espinosa et al. 2019). Esta continuidad en su uso permite sugerir que las causas de su escasa utilización en el Holoceno medio podrían deberse a que el alto nivel de las aguas durante el período limitó el acceso a algunos de sus depósitos. Asimismo, la ausencia de ocupaciones en los espacios de médanos del este y sur de la cuenca, que cuentan con los mayores depósitos de esta roca (Agnolin et al. 2018), habría incidido también en el menor uso de esta materia prima.

Resumiendo, la tecnología del Holoceno medio muestra el predominio de artefactos de procesamiento confeccionados en rocas inmediatamente disponibles, de manufactura poco costosa. Dentro de este panorama, hay una tendencia a la selección de materias primas para la confección de algunos tipos artefactuales, si bien predomina siempre el uso de rocas locales e inmediatamente disponibles. Por otra parte, en mucha menor frecuencia aparecen artefactos elaborados con anticipación como las puntas de proyectil, confeccionadas en materias primas alóctonas de óptima calidad (obsidiana) y transportadas. Las estructuras artefactuales resultan afines entre los diferentes conjuntos, indicando una modalidad de uso similar de los distintos espacios de la cuenca. Esta escasa variabilidad sería fruto de la realización de un rango acotado de actividades, que involucraban el desarrollo de tareas de procesamiento llevadas a cabo mediante una tecnología lítica poco formatizada. El predominio absoluto de estas tecnologías contrasta con la ausencia de otras como los molinos, la cerámica o las rocas termóforas destinadas al hervido, frecuentes en la región y los espacios vecinos durante el Holoceno tardío (Cassiodoro y Tchilinguirian, 2007; Cassiodoro et al., 2014; Goñi, 2010). Estas diferencias en el tipo de artefactos empleados apuntarían a estrategias de procesamiento que involucraban una baja inversión en la manufactura de tecnología. En términos de Bettinger y coautores (2006, ver también Kelly, 2013), se trataría de una tecnología "barata", poco costosa en términos de tiempo y materias primas, asociada a tareas de procesamiento que involucran una baja inversión de energía.

En base a la evidencia descripta, pueden esbozarse algunas ideas acerca de la movilidad de estas poblaciones. Los grupos cazadores del Holoceno medio ocuparon un paisaje posiblemente deshabitado, diferente al existente actualmente, con una mayor humedad y una distribución más homogénea de fuentes de agua, pasturas y presas. Otros recursos como el reparo o la leña, en cambio, probablemente tuvieron una distribución discontinua a lo largo de todo el Holoceno. Este paisaje habría presentado una menor fragmentación en parches que la documentada para el Holoceno tardío, por lo que habría favorecido una movilidad con un menor componente logístico que la desarrollada en momentos posteriores. Las evidencias apoyan en parte esta interpretación, señalando el 
desarrollo de una gama de actividades muy similar entre las diferentes geoformas. En este sentido, los conjuntos presentes muestran que las tareas limitadas llevadas a cabo en los diferentes sitios son muy similares, careciendo de la variabilidad observada en momentos posteriores (Agnolin, 2019; Cassiodoro et al., 2014). De acuerdo a esto, puede considerarse que la movilidad del Holoceno medio en la cuenca incluyó estrategias logísticas, representadas por los sitios analizados, si bien con una menor variabilidad y diferenciación que las desarrolladas durante el Holoceno tardío. Un panorama similar con relación a la riqueza y variabilidad del registro se da en las mesetas altas que rodean al Cardiel, como la del Strobel. En esta última, para el Holoceno medio existe un registro compuesto por escasas puntas de proyectil apedunculadas, en su mayoría aisladas y una pequeña cantidad de grabados rupestres. En contraste, para el Holoceno tardío el registro es más abundante, pero además presenta tipos de evidencia previamente ausentes, como los parapetos (más de 300), una gran diversidad y cantidad de grabados rupestres, diversos tipos de concentraciones de material lítico y entierros (Flores Coni, 2018; Re et al., 2017).

En cuanto a la ocupación del espacio, la distribución de los hallazgos y su concentración en la geoforma de Cañadones, principalmente en su sector sur, señalan que estos grupos habrían focalizado su ocupación en puntos específicos de la región. Asimismo, el fuerte predominio de materias primas locales e inmediatamente disponibles a los sitios apunta a cierta estabilidad en el asentamiento, o al menos un grado de continuidad en el cocimiento de la región suficiente como para la utilización de sus recursos líticos. Esto no implica necesariamente una baja movilidad, ya que la presencia constante de obsidiana señala el acceso a espacios situados a una distancia considerable, como Pampa del Asador.

En resumen, las poblaciones que ocuparon la región durante el Holoceno medio habrían hecho uso de un espacio amplio que no contaba con ocupaciones previas de importancia, colonizándolo en el proceso. Las mismas utilizaron los recursos locales, empleando una movilidad logística y una tecnología poco costosa, en un ambiente más homogéneo que el actual. Con posterioridad, al avanzar el proceso de desecación, las poblaciones locales modificaron sus estrategias de movilidad y uso del espacio, estableciéndose de manera permanente en la cuenca (Goñi et al 2014, entre otros). En este nuevo escenario, la cuenca del Cardiel se convirtió en un espacio de concentración de poblaciones, adquiriendo un rol diferente al de momentos previos, caracterizados por su relativo aislamiento.

\section{Conclusiones}

Durante el Holoceno medio, el centro-oeste de Santa Cruz atravesó un período caracterizado por episodios de altos niveles lacustres y mayor humedad ambiental que el actual. El resultado fue un paisaje con amplios sectores cubiertos por las aguas y una mayor homogeneidad en la distribución de los recursos, diferente al de los últimos 3000 años. La dinámica de poblamiento de este período muestra una estrecha relación con dicho panorama climático/ambiental, señalando ocupaciones distribuidas en espacios acotados y asociadas a un uso equiparable de los diferentes sectores de la cuenca.

De acuerdo a esto, el proceso de ocupación de la cuenca del lago Cardiel a lo largo del todo el Holoceno muestra una constante interacción con las dinámicas ambientales. En este proceso las poblaciones modificaron el uso del espacio de acuerdo a sus posibilidades y necesidades, dejando un complejo registro arqueológico.

Liniers, Buenos Aires, Mayo de 2021

\section{Agradecimientos}

A Rafael Goñi y Gisela Cassiodoro, que corrigieron este manuscrito y contribuyeron a mejorarlo substancialmente, a Diego Rindel, Silvana Espinosa, Juan Belardi, Juan Dellepiane, Francisco Guichón, Josefina Flores Coni, Anahí Re, Sebastián Pasqualini, Victoria Lange, Rocío Guichón, Milena Morlesín, Mariana Espinosa y Milena Daldin, que dirigieron o participaron en los trabajos de campo y a Celso Lillo, Carlos Nuevo Freire y la familia Martínez, que nos dieron acceso a los campos y nos brindaron su hospitalidad. Finalmente, a los evaluadores anónimos, que con sus valiosas observaciones contribuyeron a mejorar este trabajo. El INAPL brindó sus instalaciones para desarrollar esta investigación, mientras que el trabajo de campo fue llevado a cabo con el apoyo de los proyectos UBACYT 20020170100150BA y PICT2018-03813.

\section{Bibliografía}

Agnolin, A. (2016). Un acercamiento tecnológico a las variaciones en el uso de los aleros: el caso de los cañadones del lago Cardiel (Río Chico, Santa Cruz). En Actas del XIX Congreso Nacional de Arqueología Argentina (pp. 135-137). Tucumán: Instituto Miguel Lillo.

Agnolin, A. (2019). Aspectos tecnológicos de registro arqueológico de la cuenca del Lago Cardiel y su relación con los cambios climático/ambientales del Holoceno. [tesis de doctorado, Facultad de Filosofía y Letras, Universidad de Buenos Aires]

Agnolin, A. (2020). Variaciones en la tecnología y el uso de diferentes escalas: un abordaje desde el alero Los Guanacos 1 (Santa Cruz, Argentina). La Zaranda De Ideas, 18(2), 80-100. 
Agnolin, A., Cassiodoro, G. \& Espinosa, S. (2018). Recursos líticos de la cuenca del lago Cardiel (Santa Cruz): nuevas prospecciones e implicancias para la arqueología regional. Relaciones de la Sociedad Argentina de Antropología $\mathrm{XLIII}(1), 1-16$.

Andrefsky, W. (1994). Raw material and the organization of technology. American Antiquity, 59(1), 21-34.

Ariztegui D., Anselmetti, F., Kelts, K., Seltzer, G. \& D'Agostino, K. (2001). Identifying paleoenvironmental change across South and North America using highresolution seismic stratigraphy in lakes. En V. Markgraf (Ed.). Interhemispheric Climate Linkages (pp. 227-240). Academic Press.

Ariztegui D., Anselmetti, F., Gilli, A. \& Waldmann, N. (2008). Late Pleistocene environmental changes in Patagonia and Tierra del Fuego: a limnogeological approach. En J. Rabassa (Ed.). The Late Cenozoic of Patagonia and Tierra del Fuego (pp. 241-253). Elsevier Science.

Aschero, C. (1975). Ensayo para una clasificación morfológica de artefactos líticos aplicada a estudios tipológicos comparativos. Informe Técnico en posesión de CONICET, Buenos Aires.

Aschero, C. (1983). Ensayo para una clasificación morfológica de artefactos líticos aplicada a estudios tipológicos comparativos: Apéndice A-C. Buenos Aires: Cátedra de Ergología y Tecnología, Facultad de Filosofía y Letras, UBA.

Aschero, C., Goñi, R., Civalero, T., Molinari, R., Espinosa, S., Guráieb, G. \& Bellelli, C. (2005). Holocenic Park: Arqueología del Parque Nacional Perito Moreno (PNPM). Anales de la Administración de Parques Nacionales XVII, 71-119.

Bar-Yosef, O. \& Kuhn, S. (1999). The big deal about blades: Laminar technologies and human evolution. American Anthropologist 101 (2), 322-338.

Belardi, J., Goñi, R., Bourlot, T. \& Aragone, A. (2003). Paisajes arqueológicos en la cuenca del Lago Cardiel (Provincia de Santa Cruz, Argentina). Magallania 31, 95-106.

Belardi, J., Espinosa, S., Barrientos, G., Carballo Marina, F., Re, A., Campan, P., Súnico, A. \& Guichón, F. (2013). Arqueología de las mesetas de San Adolfo y Cardiel Chico: Interferencias acerca de las estrategias de movilidad y caza en el SO de Santa Cruz. En A. Zangrando \& R. Barberena (Eds.). Tendencias teórico-metodológicas y casos de estudio en la arqueología de Patagonia (pp. 261-270). Museo de Historia Natural de San Rafael.
Belardi, J., Cassiodoro, G., Goñi, R., Glascock, M. \& Sunico, A. (2015). Siltstone from Southern Patagonia: Its Source and Archaeological Artifact Distribution in Santa Cruz Province, Argentina. Geoarchaeology: An International Journal 30, 223-237.

Bettinger, R., Winterhalder, B. \& McElreath, R. (2006). A simple model of technological intensification. Journal of Archaeological Science 33, 538-545.

Binford, L. (1977). Forty-seven Trips: A Case Study in the Character of Archaeological Formation Processes. En R. Wright (Ed.). Stone Tools as Cultural Markers: Change, Evolution and Complexity (pp. 24-36). Humanities Press.

Binford, L. (1979). Organization and formation processes: looking at curated technologies. Journal of Anthropological Research 35(3), 255-273.

Binford, L. (1980). Willow smoke and dogs' tails: Huntergatherer settlement systems and archaeological site formation. American Antiquity 45(1), 4-20.

Binford, L. (2001). Constructing Frames of Reference. University of California Press.

Borrero, L. (1987). Variabilidad de sitios arqueológicos en la Patagonia meridional. En Primeras Jornadas de Arqueología de la Patagonia (pp. 41-45). Rawson: Publicación del Gobierno de la Provincia de Chubut.

Borrero, L. (1989-1990). Evolución cultural divergente en la Patagonia Austral. Anales del Instituto de la Patagonia 19, 133-140.

Bourlot, T. (2012). Zooarqueología de sitios a cielo abierto en el lago Cardiel, provincia de Santa Cruz: Fragmentación ósea y consumo de grasa animal en grupos cazadores-recolectores del Holoceno tardío. BAR International Series.

Cassiodoro, G. (2016). Variabilidad tecnológica en sectores altos del centro-oeste de Santa Cruz durante el Holoceno medio y tardío. Arqueología 22(2), 335359.

Cassiodoro, G \& Tchilinguirian, P. (2007). Análisis petrográficos de cerámicas en el noroeste de la provincia de Santa Cruz. En F. Morello, M. Martinic, A. Prieto \& G. Bahamonde (Eds.) Arqueología de Fuego-Patagonia. Levantando piedras, desenterrando huesos...y develando arcanos (pp. 839-852). CEQUA.

Cassiodoro, G., Rindel, D., Goñi, R., Re, A., Tessone, A., García Guraieb, S., Belardi, J. B., Espinosa, S., Nuevo Delaunay, A., Dellepiane, J., Flores Coni, J., Guichón, F., Martinez, C. \& Pasqualini, S. (2013). Arqueología 
del Holoceno medio y tardío en Patagonia meridional: poblamiento humano y fluctuaciones climáticas. Diálogo Andino, 41, 5-23.

Cassiodoro, G., Espinosa, S., Re, A., Belardi, J., Nuevo Delaunay, A., Piriz, F. \& Durou, G. (2014). Tecnología de la cuenca del lago Cardiel. En R. Goñi, J. B. Belardi, G. Cassiodoro \& A. Re (Eds.) Arqueología de las Cuencas de los Lagos Cardiel y Strobel. Poblamiento Humano y Paleoambientes en Patagonia (pp. 67-95). Aspha Ediciones.

Cassiodoro, G., Flores Coni, J., Agnolin, A. \& Goñi, R. (2020). Caracterización de puntas de proyectil apedunculadas. Un aporte al poblamiento del centrooeste de la provincia de Santa Cruz (Argentina). Revista del Museo de La Plata 5(1), 126-141.

Crivelli Montero, E. \& Fernández, M. (2004). Algunas propuestas para el análisis cuantitativo de conjuntos líticos. En A. Acosta, M. Loponte \& M. Ramos (Eds.). Temas de Arqueología. Análisis lítico (pp. 27-57). SAA.

Cusminsky, G., Schwalb, A., Pérez, A., Pineda, D., Viehberg, F., Whatley, R., Markgraf, V., Gilli, A., Ariztegui, D. \& Anselmetti, F. (2011). Late Quaternary environmental changes in Patagonia as inferred from lacustrine fossil and extant ostracodes. Biological Journal of the Linnean Society 103, 397-408

Dincauze, D. (2000). Environmental Archaeology: Principals and Practice. Cambridge University Press.

Dunnell, R. \& Dancey, W. (1983). The siteless survey: A regional scale data collection strategy. En M. Schiffer (Ed.). Advances in Archaeological Method and Theory (pp. 267-287). New York: Academic Press.

Escola, P. (2004). La expeditividad y el registro arqueológico. Chungara 36, 49-60.

Espinosa, S. \& Goñi, R. (1999). Viven! Una fuente de obsidiana en la Pcia. de Santa Cruz. En Soplando en el Viento. Actas de las III Jornadas de Arqueología de la Patagonia (pp. 177-188). INAPL-UN de comahue.

Flores Coni, J. (2018). Poblamiento humano y uso del espacio en la meseta del Strobel (provincia de Santa Cruz). Un análisis sobre la variabilidad tecnológica durante el Holoceno. [tesis de doctorado. Facultad de Filosofía y Letras, Universidad de Buenos Aires].

Gilli, A., Anselmetti, F., Ariztegui, D., Platt Bradbury, J., Kelts, K., Markgraf, V. \& Mckenzie, J. (2001). Tracking abrupt climate change in the Southern Hemisphere: a seismic stratigraphic study of Lago Cardiel, Argentina
(49 S). Terra Nova 13(6), 443-448.

Gilli, A., Ariztegui, D., Anselmetti, F., Mc Kenzie, J., Markgraf, V., Hajdas, I. \& Mc Culloch, R. (2005). MidHolocene strengthening of the Southern Westerlies in South America- Sedimentological evidences from lago Cardiel, Argentina (495). Global and Planetary Change 49, 75-93.

Goñi, R. (2000). Arqueología de momentos históricos fuera de los centros de conquista y colonización: un análisis de caso en el sur de la Patagonia. En S. Espinosa (Ed.) Desde el País de los Gigantes. Perspectivas Arqueológicas en Patagonia (pp. 283296). UNPA.

Goñi, R. (2010). Cambio climático y poblamiento humano durante el Holoceno tardío en Patagonia meridional. Una perspectiva arqueológica. [tesis de doctorado. Facultad de Filosofía y Letras, Universidad de Buenos Aires, Buenos Aires].

Goñi, R. \& Belardi, J., (2014). El proyecto de arqueología de los lagos Cardiel y Strobel. El poblamiento de la estepa santacruceña. En R. Goñi, J. Belardi, G. Cassiodoro \& A. Re (Eds.) Arqueología de las cuencas de los lagos Cardiel y Strobel. Poblamiento humano y paleoambientes en Patagonia (pp. 17-29). Aspha ediciones.

Goñi, R. \& Barrientos, G., (2004). Poblamiento tardío y movilidad en la cuenca del lago Salitroso. En T. Civalero, P. Fernández \& G. Guráieb (Eds.). Contra Viento y Marea. Arqueología de Patagonia (pp. 313324). INAPL-SAA.

Goñi, R., Barrientos, G. \& Cassiodoro, G., (2000-2002). Condiciones previas a la extinción de las poblaciones humanas del sur de Patagonia: una discusión a partir del análisis del registro arqueológico de la cuenca del lago Salitroso. Cuadernos del Instituto Nacional de Antropología y Pensamiento Latinoamericano 19, 249266.

Goñi, R., Belardi, J., Espinosa, S. \& Savanti, F. (2004). Más vale tarde que nunca: cronología de las ocupaciones cazadoras- recolectoras en la cuenca del lago Cardiel (Santa Cruz, Argentina). En T. Civalero, P. Fernández \& G. Guraieb (Eds.). Contra Viento y Marea. Arqueología de la Patagonia (pp. 237-248). INAPL.

Goñi, R., Espinosa, S., Belardi, J., Molinari, R., Savanti, F., Aragone, A., Cassiodoro, G., Lublin, G. \& Rindel, D. (2005). Poblamiento de la estepa patagónica: cuenca de los Lagos Cardiel y Strobel. En Actas del XIII Congreso Nacional de Arqueología Argentina (pp. 1-18). Editorial Brujas.

Goñi, R., Belardi, J., Cassiodoro, G., Rindel, D., García 
Guraieb, S. \& Bourlot, T. (2014). Registro arqueológico y cronología de las ocupaciones cazadoras-recolectoras en la cuenca del lago Cardiel. En R. Goñi, J. Belardi, G. Cassiodoro \& A. Re (Eds.) Arqueología de los lagos Cardiel y Strobel. Poblamiento humano y paleoambientes en Patagonia (pp. 41-66). Aspha Ediciones.

Gould, R. (1980). Living Archaeology. Cambridge University Press.

Gradín, C, C. Aschero y A. Aguerre. 1987. Primeros niveles culturales en el área del río Pinturas. Estudios Atacameños 8, 118-141.

Guichón, F. (2018). Redes de información durante el Holoceno medio y tardío en Patagonia meridional. Estudio de las representaciones rupestres en la cuenca del lago Cardiel y el sur de la meseta del Strobel. [tesis de doctorado. Facultad de Filosofía y Letras, Universidad de Buenos Aires].

Hayden, B., Franco, N. \& Spafford, J. (1996). Evaluating Lithic strategies and design criteria. En G. Odell (Ed.) Stone Tools: Theoretical insights into Human Prehistory (pp. 9-45). Plenum Press, New York.

Kelly, R. (1983). Hunter-gatherer mobility strategies. Journal of anthropological research 39, 277-306.

Kelly, R. (2013). The lifeways of hunter-gatherers: the foraging spectrum. Cambridge University Press.

Markgraf, V., Bradbury, J., Schwalb, A., Burns, S., Stern, C., Ariztegui, D., Gilli, A., Anselmetti, F., Stine, S. \& Maidana, N. (2003). Holocene palaeoclimates of southern Patagonia: limnological and environmental history of Lago Cardiel, Argentina. The Holocene 13(4), 581-591.

Martínez, C., Pasqualini, S. \& Rapela, I. (2012). Alero Los Guanacos 1 lago Cardiel, Santa Cruz, Argentina. En Kuperszmit, T. Mármol, L. Mucciolo y M. Sacchi (Eds.) Entre pasados y presentes 3. Estudios contemporáneos en ciencias antropológicas (pp. 924-942). INAPL.

Morello, J., Matteucci, S., Rodriguez, A. \& Silva, M. (2012). Ecorregiones y complejos ecosistémicos argentinos. FADU-GEPAMA.

Mosquera, B. (2018). Análisis de la información radiocarbónica de sitios arqueológicos del Macizo del Deseado, provincia de Santa Cruz, Argentina. Intersecciones en Antropología 19, 25-36.

Nami, H. \& Bellelli, C. (1994). Hojas, experimentos y análisis de desechos de talla. Implicaciones arqueológicas para la Patagonia Centro-Septentrional. Cuadernos del INAPL 15, 199-224.
Nelson, M. (1991). The study of technological organization. En M. Schiffer (Ed.) Archaeological Method and Theory 3 (pp. 57-100). University of Arizona Press.

Pasqualini, S. (2014). Utilización de recursos leñosos y uso del espacio en el noroeste de Santa Cruz a partir del Holoceno tardio: un análisis antracológico de los sitios Alero Los Guanacos 1 y Cañadón Guitarra 3. [tesis de Licenciatura. Facultad de Filosofía y Letras, Universidad de Buenos Aires, Buenos Aires]

Piriz, F. (2004). Paleoplayas y ocupación humana en el lago Cardiel: sitio Patito. En T. Civalero, P. Fernández y G. Guráieb (Eds.) Contra Viento y Marea. Arqueología de Patagonia (pp. 565-570). INAPL-SAA.

Quade, J. \& Kaplan, M. (2017). Lake-level stratigraphy and geochronology revisited at Lago (Lake) Cardiel, Argentina, and changes in the Southern Hemispheric Westerlies over the last $25 \mathrm{ka}$. Quaternary Science Reviews 177, 173-188.

Re, A, Goñi, R., Flores Coni, J., Guichón, F., Dellepiane, J. \& Umaño, M. (2017). Arqueología de la meseta del Strobel (Patagonia meridional): 15 años después. Relaciones de la Sociedad Argentina de Antropología XLII(1), 33-158.

Rindel, D. (2009). Arqueología de momentos tardíos en el noroeste de la Provincia de Santa Cruz (Argentina): una perspectiva faunística. [tesis de Doctorado. Facultad de Filosofía y Letras, Universidad de Buenos Aires].

Rindel, D. \& Bourlot, T. (2014). Zooarqueología de la cuenca del lago Cardiel. En R. Goñi, J.B. Belardi, G. Cassiodoro y A. Re (Eds.). Arqueología de las cuencas de los lagos Cardiel y Strobel. Poblamiento humano y paleoambientes en Patagonia (pp. 97-116). Aspha ediciones.

Sacchi, M., Bozzuto, D., Horta, L., Fernández, N., De Nigris, M., Civalero, T. \& Aschero, C. (2016). Dataciones y circulación humana: posibles influencias de las fluctuaciones del sistema lacustre Pueyrredón- Posadas durante el Holoceno. Andes 27 (2), 1-16.

Stine, S. (1994). Extreme and persistent drought in California and Patagonia during mediaeval time. Nature 369, 546-549.

Stine, S. (2000). On the Medieval Climatic Anomaly. Current Anthropology 41(4), 627-628.

Stine, S. \& Stine, M. (1990). A record from Lake Cardiel of Climate Change in Southern America. Nature 345(6277), 705-708. 
Thomas, D. (1983). The Archaeology of Monitor Valley 2. Gatecliff Shelter. Anthropological Papers 59(1). American Museum of Natural History.
Wilmsen, E. (1970). Lithic analysis and cultural inference: A paleo-Indian case. Anthropological Papers 16. University of Arizona Press. 